Florida International University

FIU Digital Commons

School of Universal Computing, Construction, and Engineering Education

3-2019

\title{
Exemplifying the Scientific Enterprise through Diversity, Equity, and Inclusion
}

\author{
Stephen D. Secules \\ School of Universal Computing, Construction, and Engineering Education, Florida International University, \\ ssecules@fiu.edu \\ Darryl Dickerson \\ Department of Mechanical and Materials Engineering, Florida International University, ddickers@fiu.edu
}

Follow this and additional works at: https://digitalcommons.fiu.edu/succeed

\section{Recommended Citation}

Secules, S. \& Dickerson D. (March, 2019). "Exemplifying the Scientific Enterprise through Diversity, Equity, and Inclusion." Presented at the Carnegie Institution for Science. Pasadena, CA. 10.25148/ succeed.FIDC008802

This work is brought to you for free and open access by FIU Digital Commons. It has been accepted for inclusion in School of Universal Computing, Construction, and Engineering Education by an authorized administrator of FIU Digital Commons. For more information, please contact dcc@fiu.edu. 


\section{Exemplifying the Scientific Enterprise through Diversity, Equity, and Inclusion}

Workshop at Carnegie Institute 


\section{PURDUE}

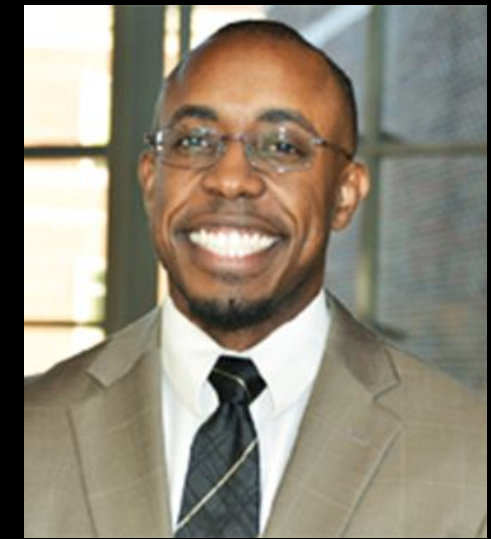

Darryl Dickerson Associate Director Minority Engineering Program

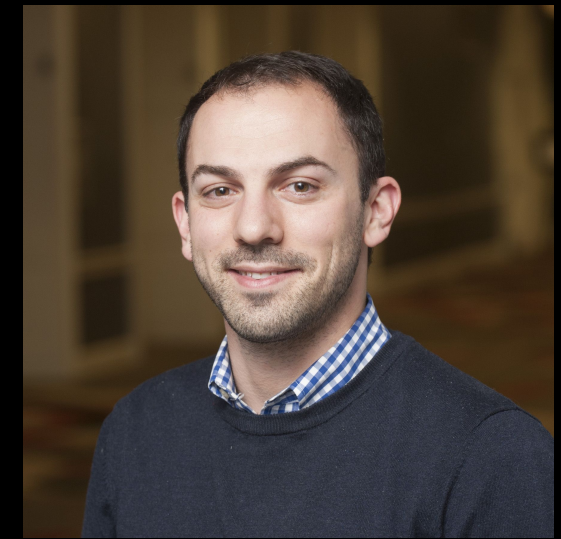

Stephen Secules

Visiting Assistant

Professor of

Engineering Education 


\section{Darryl Dickerson}

PhD, Biomedical Engineering, Purdue University

Chair of Board of Directors, National Society of Black Engineers (NSBE), 2007 2008

Pre-College Initiative Chairperson, NSBE, 2004 - 2007

Associate Director, Minority Engineering Program, 2012 - present

President and Executive Director, National Association of Multicultural

Engineering Program Advocates (NAMEPA)

Board Director, NAMEPA 2015 - present 


\section{Stephen Secules}

B.E. Engineering, M.S. Acoustics, PhD Education

Visiting Assistant Professor, Purdue University

My research is on culture and equity in Science, Technology, Engineering, and Math (STEM) educational settings

I collaborate with faculty and staff to create more inclusive institutional culture for many student groups

As a social scientist, I think critically about STEM culture and help others to too 


\section{You shared with us...}

\section{Your goals}

- "just to participate" $x 6$

- "to learn how we might build more diverse audiences for our public programs"

- "to help people who aren't affected by them understand why those things are so important"

- "concrete steps for the Carnegie leadership to take in response to this discussion, and a plan to follow up on any progress in several month's time" 
Purpose

and

Plan 


\section{Purpose}

We are researchers focused on diversity, equity, and inclusion (DEI) in STEM education and professional settings.

We believe DEI concerns all members of the scientific community.

We have come to reflect with you on the DEI mission of Carnegie and to brainstorm ways to make progress. 


\section{Plan}

Monday: Workshop to collectively brainstorm:

- What is the mission of Carnegie Institute?

- What are its key activities?

- What are its key characteristics?

And how do each of these relate to diversity, equity, and inclusion?
After the workshop: We will synthesize the findings and produce a framework to help guide future progress.

Wednesday: We will be following up with some constituent groups at the Observatories to present our initial findings and hear their perspectives. 


\section{Talking about Diversity}




\section{Suggested ground rules}

Share from your personal experience as you feel comfortable

Lean in to your "learning edge" about diversity, equity, inclusion 


\section{Icebreaker 1}

Talk in pairs:

What is one thing that people might not guess

about you when first meeting you that is important to your experience or perspective? 


\section{Icebreaker 2}

Talk in pairs:

What is one thing that people probably would guess about you that is important to your experience or perspective? 


\section{Diversity = differences among people}

Diversity means the ways we differ.

It includes the readily visible differences and the differences that may be below the surface.

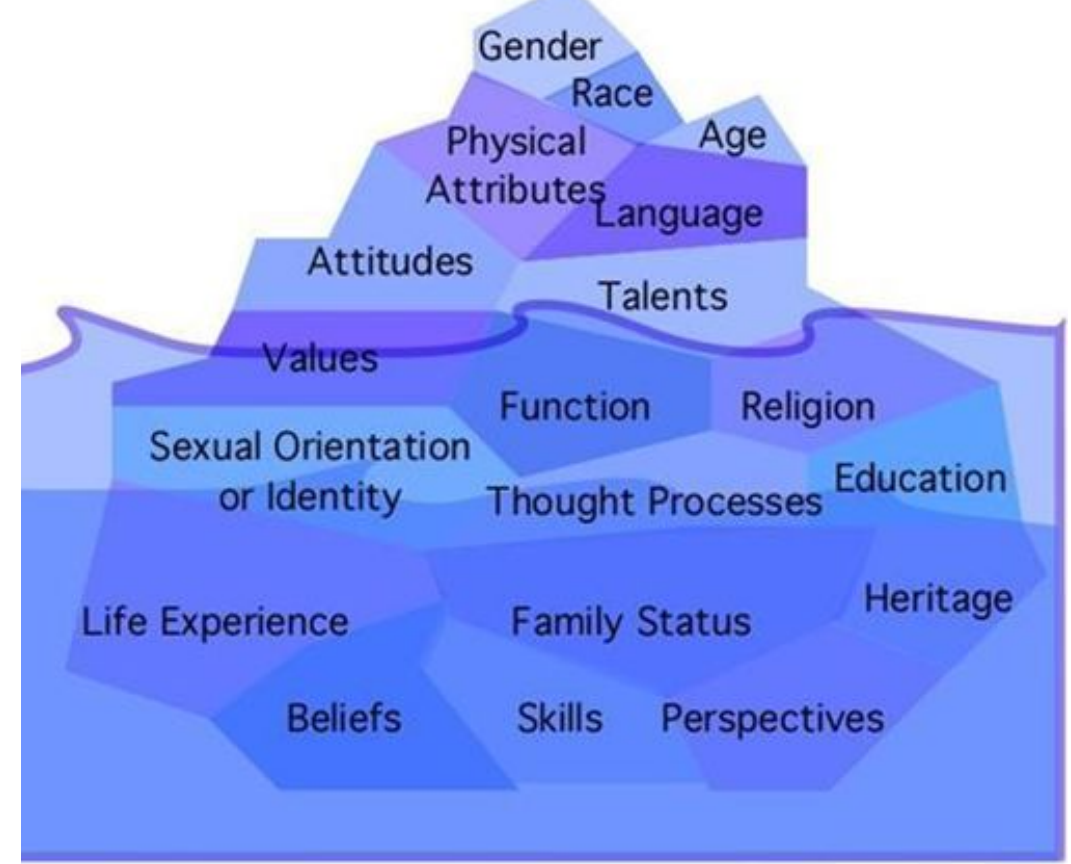




\section{Diversity = differences among people}

\section{Identity =}

- Who you are and how that positions you in relation to others

- Demographic social identities

- Roles (e.g., scientist, engineer, parent)

- We can hold multiple identities

- They can be more or less significant

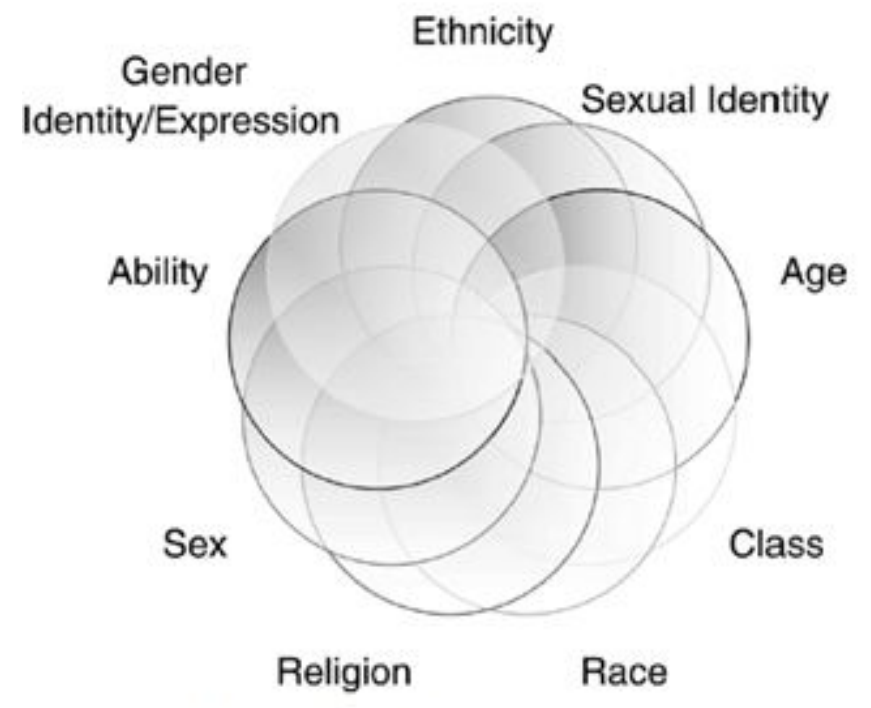
to us in different situations 


\section{Diversity}

\section{Think about Identity:}

- How do you identify in each of the following categories?

- How do most scientists identify? Why does this matter?

\begin{tabular}{|c|c|}
\hline $\begin{array}{c}\text { Social Identity } \\
\text { Categories }\end{array}$ & Social Group Members \\
\hline Race & $\begin{array}{c}\text { Black, White, Asian, Latino, } \\
\text { Native American, Multiracial }\end{array}$ \\
\hline Sex & Female, Male, Intersex \\
\hline Gender & $\begin{array}{c}\text { Men, Women, Transgender, } \\
\text { Genderqueer }\end{array}$ \\
\hline Religion & $\begin{array}{c}\text { Jewish, Muslim, Christian, } \\
\text { Hindu, Buddhist, Mormon, } \\
\text { Atheist, Agnostic }\end{array}$ \\
\hline Sexual Orientation & $\begin{array}{c}\text { Lesbian, Gay, Bisexual, } \\
\text { Heterosexual }\end{array}$ \\
\hline Class & $\begin{array}{c}\text { Owning, Poor, Upper Middle, } \\
\text { Middle, Working Class }\end{array}$ \\
\hline Ability & $\begin{array}{c}\text { Disabled, Temporarily } \\
\text { Able-Bodied }\end{array}$ \\
\hline Age & Elders, Adults, Young People \\
\hline
\end{tabular}




\begin{tabular}{|c|c|}
\hline $\begin{array}{c}\text { Social Identity } \\
\text { Categories }\end{array}$ & Social Group Members \\
\hline Race & $\begin{array}{c}\text { Black, White, Asian, Latino, } \\
\text { Native American, Multiracial }\end{array}$ \\
\hline Sex & Female, Male, Intersex \\
\hline Gender & $\begin{array}{c}\text { Men, Women, Transgender, } \\
\text { Genderqueer }\end{array}$ \\
\hline Religion & $\begin{array}{c}\text { Jewish, Muslim, Christian, } \\
\text { Hindu, Buddhist, Mormon, } \\
\text { Atheist, Agnostic }\end{array}$ \\
\hline Sexual Orientation & $\begin{array}{c}\text { Lesbian, Gay, Bisexual, } \\
\text { Heterosexual }\end{array}$ \\
\hline Class & $\begin{array}{c}\text { Owning, Poor, Upper Middle, } \\
\text { Middle, Working Class }\end{array}$ \\
\hline Ability & $\begin{array}{r}\text { Disabled, Temporarily } \\
\text { Able-Bodied }\end{array}$ \\
\hline Age & Elders, Adults, Young People \\
\hline
\end{tabular}

\section{Equity / Inequity}

- Social groups often have different status and power.

- This gives some social groups unearned advantages while others face barriers.

- Inequity can be created on group, institutional, systemic, or cultural levels.

Think about Equity:

- What does science have to do with equity/inequity? 


\section{Culture}

The things we do

automatically and don't

have to think about

Habits and norms

Climate

"The air we breathe"

Insiders and Outsiders may

notice different aspects of

culture

\section{Inclusion / Exclusion}

Inclusion of specific demographic groups.

Welcoming or hostile professional contexts.

Exclusion can be intentional or unintentional.

\section{Think about Inclusion:}

How inclusive is Carnegie? To whom? Would everyone agree with my assessment? 


\section{More suggested ground rules as we go on}

Share from your personal experience as you feel comfortable

Lean in to learning about diversity, equity, and inclusion

Avoid generalizations about entire groups of people

Assume what is shared in the conversations is confidential

Be aware of letting everyone have a turn to speak

Listen to each other

Accept imperfection from others and be kind as you disagree 


\section{Institutional Context}




\section{Areas for reflection about an Institution}

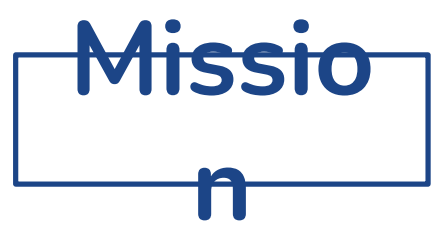

Fundamental purpose

\section{Activities}

Key areas of effort

\section{Characteristics}

Aspects of the organization 
Mission 


\section{Mission = Fundamental Purpose}




\section{Institutional Context: Carnegie Institute for Science}

\section{Mission:}

Andrew Carnegie established a unique organization dedicated to scientific discovery "to encourage, in the broadest and most liberal manner, investigation, research, and discovery and the application of knowledge to the improvement of mankind..." The philosophy was and is to devote the institution's resources to "exceptional" individuals so that they can explore the most intriguing scientific questions in an atmosphere of complete freedom. Carnegie and his trustees realized that flexibility and independence were essential to the institution's success and that tradition is the foundation of the institution today as it supports basic scientific research. 


\section{Mission:}

Andrew Carnegie established a unique organization dedicated to scientific discovery "to encourage, in the broadest and most liberal manner, investigation, research, and discovery and the application of knowledge to the improvement of mankind..." The philosophy was and is to devote the institution's resources to "exceptional" individuals so that they can explore the most intriguing scientific questions in an atmosphere of complete freedom. Carnegie and his trustees realized that flexibility and independence were essential to the institution's success and that tradition is the foundation of the institution today as it supports basic scientific research.

Over the time course of a year, what do you do within your professional role (job responsibilities) that advances the mission of Carnegie?
How can focus on diversity, equity, and inclusion advance the mission of Carnegie? 


\section{Group Brainstorm 1: Activities}




\section{Carnegie Institute of Science Activities}

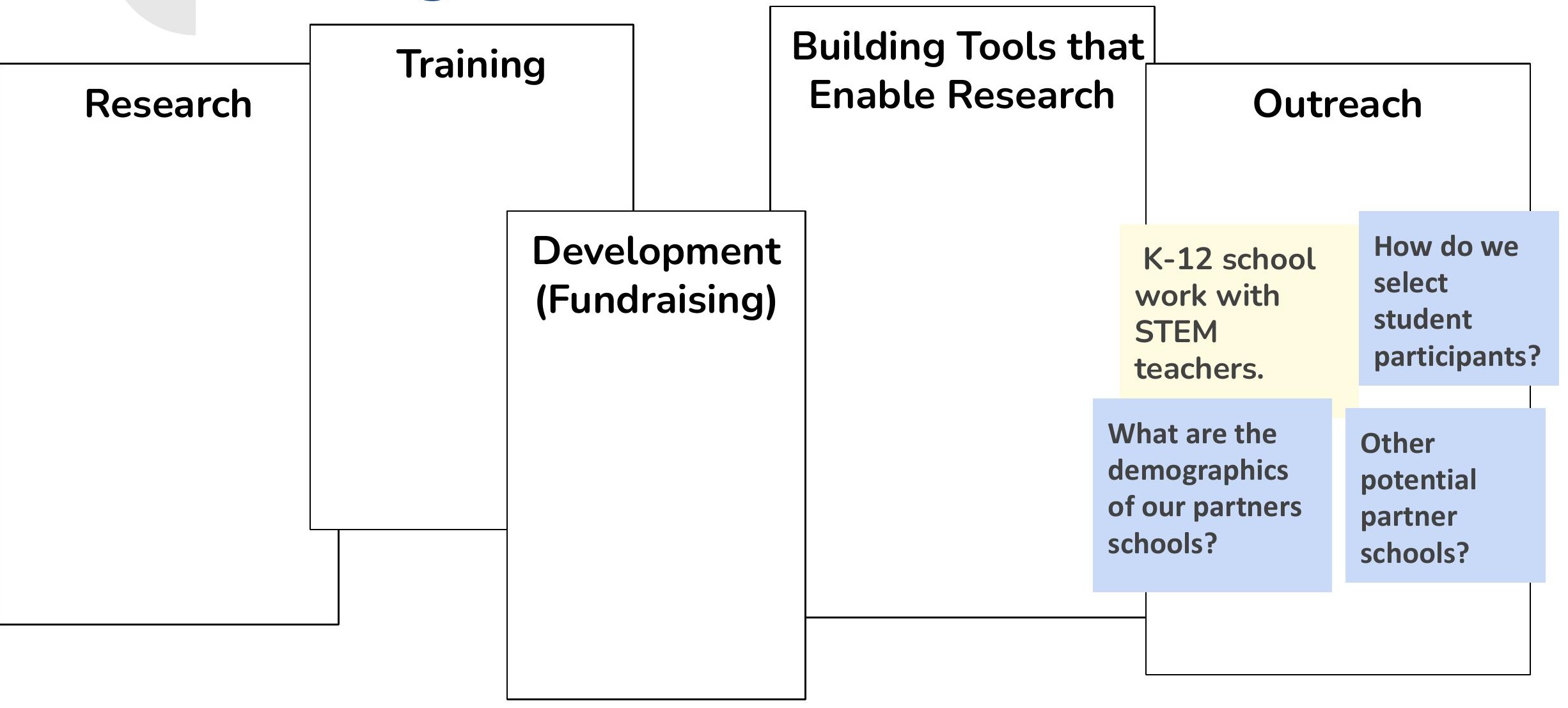



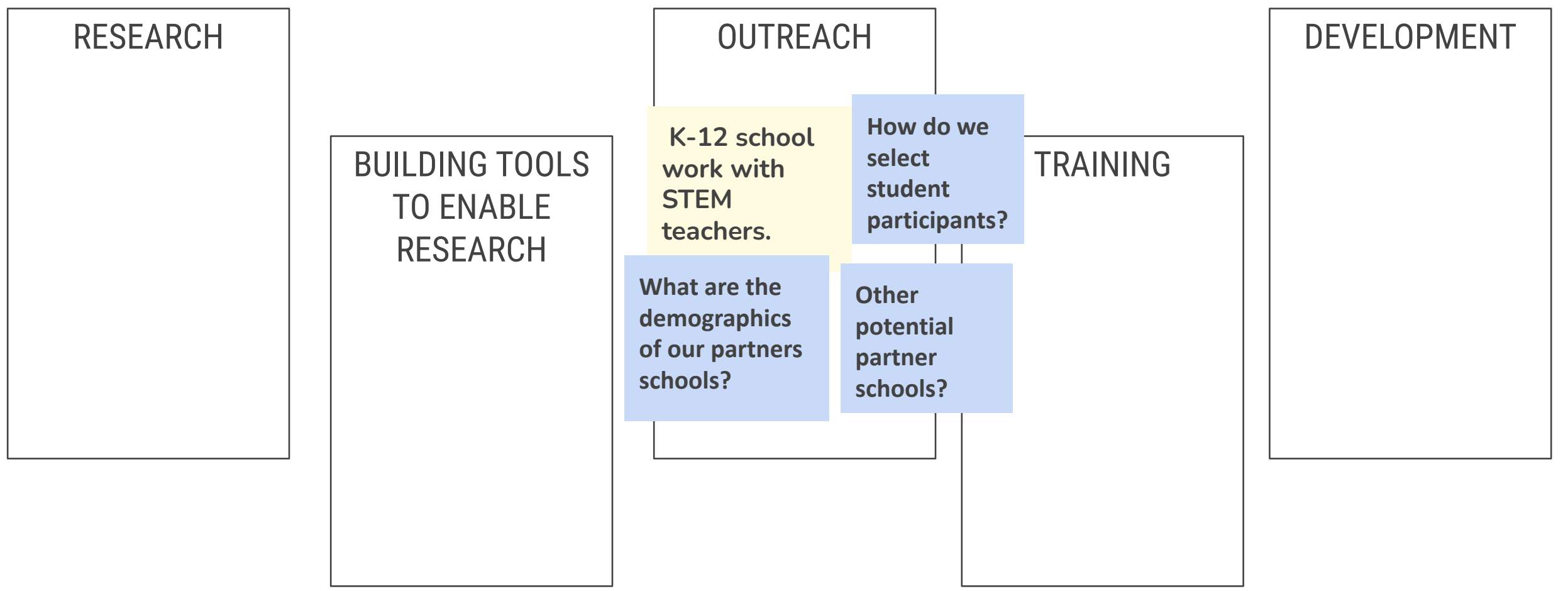
Group Brainstorm 2:

Characteristics 


\section{Carnegie Institute of Science Characteristics}

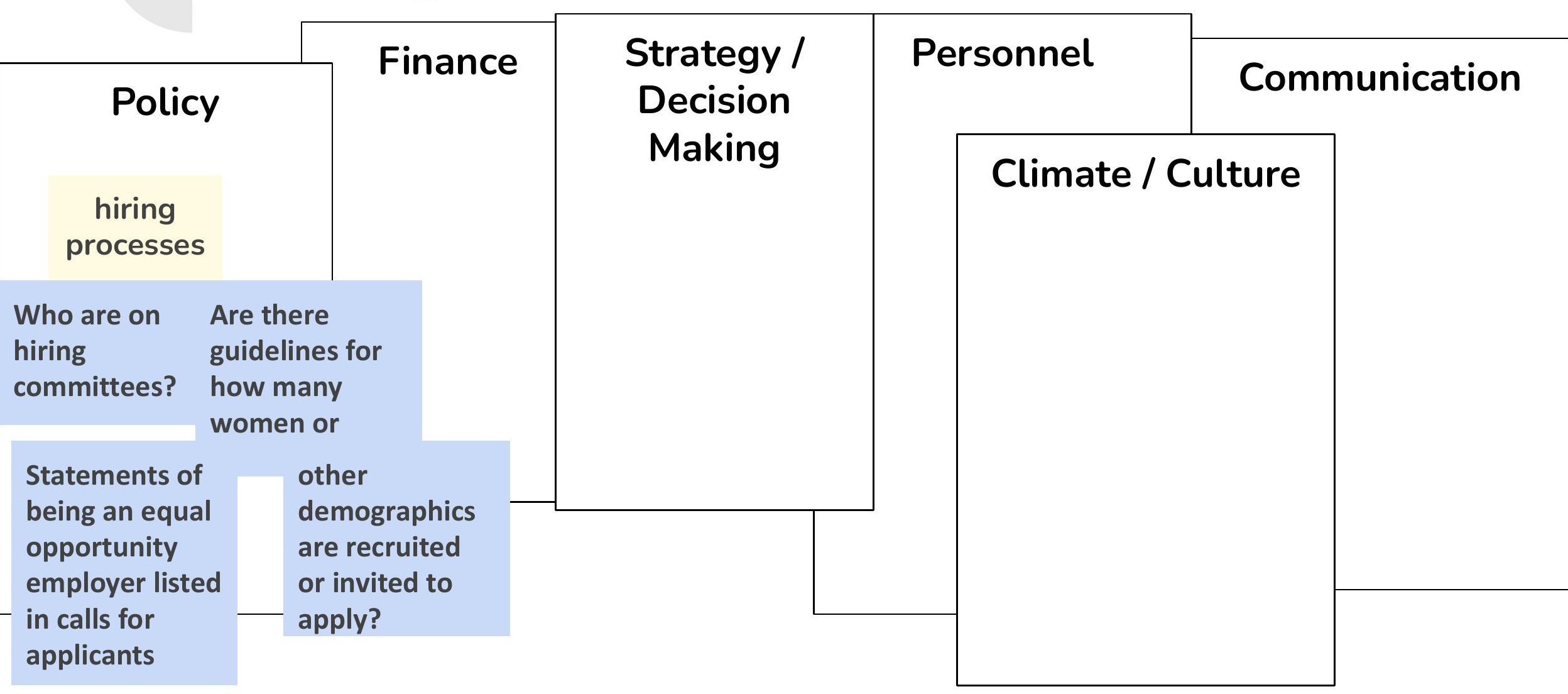


Conclusion 


\section{Individual Takeaways}

Think about and write down...

- Your Ultimate Ideal Vision: What would you like to see happen in at Carnegie?

- The Challenge: What is most pressing at Carnegie regarding DEl?

- Shorter Term Vision: How could things look differently within a year?

- Your Influence: What can you do from your seat at Carnegie to advance towards the vision? 


\section{Community Takeaways}

Holding Yourself and Each Other Accountable

Developing a Shared Vision for DEl at Carnegie (to be continued on Wednesday)

Resources from us (a checklist of questions to ask) 


\section{Thank you for participating!}

If you have more thoughts, feel free to email us ssecules@purdue.edu,ddickerson@purdue.edu.

Or respond anonymously at: http://tinyurl.com/carnegieDEl 